\title{
Differences in Small Plot and On-Farm Trials for Yield Response to Foliar Fungicide in Soybean
}

Yuba R. Kandel and Catherine L. Hunt, Iowa State University, Department of Plant Pathology and Microbiology, Ames, IA 50011; Peter M. Kyveryga $^{\dagger}$ and Tristan A. Mueller, Iowa Soybean Association, Ankeny, IA 50023; and Daren S. Mueller, ${ }^{\dagger}$ Iowa State University, Department of Plant Pathology and Microbiology, Ames

\begin{abstract}
Soybean yield response variability to foliar fungicide applications was evaluated in on-farm replicated strip trials (OFTs) and small-plot trials (SPTs) from 2008 through 2015 in Iowa. A total of 230 OFTs and 49 SPTs were compared for yield response to pyraclostrobin, pyraclostrobin + fluxapyroxad, or trifloxystrobin + prothioconazole fungicides. OFTs ( 18 to $55 \mathrm{~m}$ wide and 200 to $800 \mathrm{~m}$ long strips) were harvested with farmers' combines equipped with yield monitors and GPS, while SPTs (3.0 to $4.6 \mathrm{~m}$ wide and 10.7 to $15.3 \mathrm{~m}$ long plots) were harvested by small research plot combines. Variance component and power analyses were conducted with a subset of data consisting of 12 OFTs and SPTs, each

with pyraclostrobin and evaluated in 2008 and 2009. While average yield responses were similar, the residual random yield variation was smaller in OFTs than SPTs. Power analysis showed that SPTs need more replications than OFTs to detect the same overall treatment differences. To detect a yield response of $134 \mathrm{~kg} / \mathrm{ha}$, it would require at least three treatment replications with 12 locations in OFTs and seven replications with 12 locations in SPTs. Researchers need to acknowledge the differences in statistical power of detecting yield responses to foliar fungicide on soybean in different types of field experiments, especially with smaller plot sizes in situations with less foliar disease.
\end{abstract}

Fungicide use in soybean (Glycine $\max$ [L.] Merr) has increased since the early 2000s in the United States and Canada. Fungicides are generally applied to manage foliar diseases, but foliar applications are sometimes made with the expectation of increasing yield even in the absence of foliar diseases (Mueller et al. 2013). The most frequently observed foliar fungal diseases of soybean in the northern U.S. and Canada are Septoria brown spot (Septoria glycines Hemmi), frogeye leaf spot (Cercospora sojina Hara), and Cercospora leaf blight (C. kikuchi [T. Matsumoto and Tomoy] M.W. Gardner) (Kandel et al. 2016). Septoria brown spot is usually limited to the lower canopy and rarely causes significant yield losses. The other two diseases can be yield limiting if observed in high levels, but they are usually not major threats to soybean production in the northern U.S. or Canada (Allen et al. 2017; Kandel et al. 2016).

Claims of yield increases from physiological benefits of fungicides, even in the absence of foliar diseases, is one reason for the increased use of foliar fungicides in field crops (Wise and Mueller 2011). Although industries primarily promote quinone outside inhibitor (QoI) fungicides for physiological benefits, yield response to fungicide in university studies (Garichar 2013; Swoboda and Pedersen 2009) in the absence of, or in low levels of disease, has been inconsistent. A recent report (Kandel et al. 2016), which analyzed data from university research trials conducted over multiple locations and years, suggested that fungicides can increase soybean yield in the absence of disease, but that the applications were profitable approximately $14 \%$ of the time based on the average market price of soybean and application costs between 2008 and 2014.

The inconsistency of the reported benefits of foliar fungicides between results from fungicide manufacturers and public studies could be related to differences in experimental plot size (Tedford et al. 2017). They reported that the yield responses observed in smallplot trials were less than responses observed in larger field-scale trials and on-farm unreplicated strip trials (also referred as commercialstrip trials) in corn (Zea mays L.). Most university trials for evaluating fungicides are conducted as small-plot research trials (SPTs),

${ }^{\dagger}$ Corresponding authors: Daren S. Mueller, E-mail: dsmuelle@iastate.edu; and Peter M. Kyveryga, E-mail: PKyveryga@iasoybeans.com

Accepted for publication 7 September 2017.

C 2018 The American Phytopathological Society which are easier to manage and to collect in-field/scouting data (e.g., disease incidence and severity, insect abundances, plant characteristics) when compared with larger plots. However, previous studies suggest that the influence of borders and alleys in small plots may affect response to fungicides (Rebetzke et al. 2014; Vincelli and Lee 2015; Wang et al 2013). Therefore, implementing a valid experimental design is critical for rigorously assessing possible fungicide benefits in crop production.

Since on-farm replicated or large-plot research is logistically more difficult, it is a common practice to test fungicides in nonreplicated large plots. Previous research reporting greater yield response to fungicide in commercial trials in corn was also nonreplicated (Tedford et al. 2017). Without treatment replications, it is difficult to determine whether differences between nonreplicated plots are the result of the fungicide treatment or simply due to experimental error or fieldrelated variability unrelated to fungicide treatment. However, replicated on-farm experiments can also be conducted to evaluate foliar fungicides on soybean. For example, pyraclostrobin (Headline, BASF Corporation, Research Triangle Park, NC) was previously evaluated in 282 on-farm replicated strip trials (OFTs) in Iowa between 2005 and 2009 (Kyveryga et al. 2013).

Because one of the main objectives of field experiments is to show whether the observed yield differences are statistically significant, the hypothesis testing principles are used in analyses. The validity of the null hypothesis (the same treatment yield or yield differences are zero) are confirmed by $P$-values of significance testing. When the null hypothesis is rejected and the $P$-values are smaller than the level of significance $(\alpha)$, the common question is how often a given experiment can detect significant yield differences. Then, statistical power values can be useful. In simple terms, statistical power is the probability of detecting the treatment effect by a study, when the treatment effect is detectable. Statistical power is also described as the probability of correctly rejecting a null hypothesis when it is false, and is inversely related to the probability of Type II error (fail to reject the null hypothesis when it is false).

Statistical power can be affected by many interrelated factors: effect size (the difference between treatments), sample size $(\mathrm{N})$, and the criteria or choice of level of statistical significance $(\alpha)$, and desired level of properly ascertaining the treatment effect. For example, a field experiment may not show statistically significant yield differences because of the low power. Although never reported, power values can add significant and practical value for decision making when considering foliar fungicide applications on soybean. Field trials with low statistical power are not as efficient as those with high power. 
The most common power value is $80 \%$ (Gelman and Hill 2007), indicating that a specific trial has an 8 in 10 chance to detect a significant yield response given that the true yield response is detectable.

In the current study, the overall goal was to compare small-plot research and field-scale on-farm trials for yield response to fungicide application on soybean. More specifically, we analyzed how plot size influences the statistical power and calculated the sample size of trial locations and replications required to detect different yield responses to fungicide under a certain level of significance and desired power.

\section{Materials and Methods}

On-farm trials. Fields for all the OFTs were selected by the farmers between 2008 and 2015. A single soybean variety was planted in each trial and all other management practices were the same within the trial area. All inputs other than fungicides were applied across the entire field at the discretion of each farmer. Fungicides that contained a QoI active ingredient (FRAC 11; FRAC 2017) were applied with a ground sprayer or an airplane. The fungicides evaluated included pyraclostrobin (as $430 \mathrm{ml} / \mathrm{ha}$ of Headline, BASF), pyraclostrobin + fluxapyroxad (as $292 \mathrm{ml} / \mathrm{ha}$ of Priaxor, BASF), or trifloxystrobin + prothioconazole (as $292 \mathrm{ml} / \mathrm{ha}$ of Stratego YLD, Bayer CropScience, Research Triangle Park, NC). Pyraclostrobin and trifloxystrobin are QoI fungicides, fluxapyroxad is a succinate dehydrogenase inhibitor (SDHI, FRAC 7) fungicide, and prothioconazole is a demethylation inhibitor (DMI, FRAC 3) fungicide. Each trial had a minimum of three replications. Strips or experimental units were 200 to $800 \mathrm{~m}$ long and 18 to $55 \mathrm{~m}$ wide. The fungicides were applied at the R2 or $\mathrm{R} 3$ growth stage and application information was recorded with a monitor equipped with a GPS. The majority of the applications (95\%) were done using ground sprayers and the remaining $5 \%$ of trials were done via aerial applications. Additional information regarding the on-farm study design, treatment applications, and data collection are mentioned in Kyveryga et al. (2013).

Small-plot experiments. Field trials were conducted at three to seven Iowa State University (ISU) research farms from 2008 to 2015 (Fig. 1, Table 1). Fields were cultivated before planting and corn was the previous crop at all locations. Plot size was slightly different across the locations and years. In 2008, each plot was four rows wide on $76.2 \mathrm{~cm}$ centers and $10.7 \mathrm{~m}$ long. In the trials conducted between 2009 and 2015, plots were six rows wide on $76.2 \mathrm{~cm}$ centers and ranged from 10.7 to $15.3 \mathrm{~m}$ long. Soybean seed was planted between April 29 and June 13 at 309,406 to 465,347 seed/ha. The research design was a randomized complete block with four to six replications at each location. The same fungicides evaluated in the OFTs were selected as a subset for the SPTs. Fungicides were applied to the middle two rows of each plot in 2008 and the middle four rows of each plot between 2009 and 2015 at the beginning pod growth stage (R3; Fehr et al. 1971). Fungicide spray applications were made with a backpack sprayer powered by a $\mathrm{CO}_{2} \operatorname{tank}(\mathrm{R} \& \mathrm{D}$ Sprayers, Opelousas, LA) and a hand-boom calibrated to spray 187 liters/ha at $241 \mathrm{kPa}$ using flat fan XR 11002 nozzles (TeeJet, Glendale Heights, IL) in 2008 to 2012 and with a self-propelled research sprayer powered by a $\mathrm{CO}_{2}$ tank using TT 11002 (TeeJet) nozzles that delivered fungicides in 142 liters/ha at $241 \mathrm{kPa}$ in 2014 and 2015. All fungicide applications included the nonionic surfactant Induce (Helena Chemical Company, Collierville, $\mathrm{TN})$ at $0.3 \%(\mathrm{v} / \mathrm{v})$ of the product. Other agronomic practices such as herbicide application and nutrient management were followed per the Iowa State University Extension Service recommendations.

Disease and yield response. Foliar disease observations were collected between the R5 and R6.5 growth stages as the percentage of leaf area covered by disease in SPTs from the center two rows of each plot. Disease severity on 20 leaflets each from the upper and lower canopies of each plot was assessed for the fungal diseases present. In 2008, disease data were collected in the middle two rows of each plot. In 2009 through 2015, disease data were collected from the second and fifth rows.

OFTs were mechanically harvested with farmers' equipment that had yield monitors equipped with GPS. Harvest data were overlaid with the fungicide application maps to verify that the harvest data matched with the treatment application. Color-infrared (CIR) digital aerial images were composed of the near-infrared (NIR), red, and green spectral bands of the soybean canopy taken in each field in mid or late August (R6, R7, and R8 growth stages). The imagery was used to verify treatment locations, identify possible application errors, and other potential management problems within fields. Data were excluded if soybean yield was affected by soil compaction, previous field history, or change in variety in the trial area.

The two center rows from each plot were mechanically harvested, using a small plot combine at harvest maturity (R8; Fehr et al. 1971), which ranged from 22 September to 3 November. Grain yield was adjusted to $13 \%$ moisture.

Analysis of variance and variance component. Analysis of variance (ANOVA) was performed separately on SPT and OFT data, but following the same protocol and statistical methods. Mean yield responses to fungicides, defined as the yield of fungicide-treated plots minus the yield of the nontreated control plots, were compared from each year (Table 2). A mixed effect model was applied. Fungicide was considered as a fixed factor, and location and replication within a location were considered as random factors.

The variance component analysis allows us to assess the amount of variation associated with each random effect factor after adjustment for the fixed effect of the treatments. Variance component analysis was conducted with a subset of data consisting of 12 OFTs and SPTs with pyraclostrobin evaluated in 2008 and 2009. All locations were used in both years for the SPTs. A subsample of six OFTs from both years, for 12 locations in total, was selected based on proximity to SPTs to represent similar environmental conditions observed in both types of trials (Fig. 1). Using yield data from individual replications, a mixed effects model was used to estimate variance components for the random effects of location, replication, and residual error. The random effect estimates represent inferences for a larger population of situations than those observed in the study. The treatment effect was considered as fixed. Approximate $90 \%$ confidence intervals were estimated for standard deviations for the random effects. Mean variances from the random effect were used to estimate the percentage of contribution of each random effect component (location, replication, and residual error) to the total random variation. All calculations were

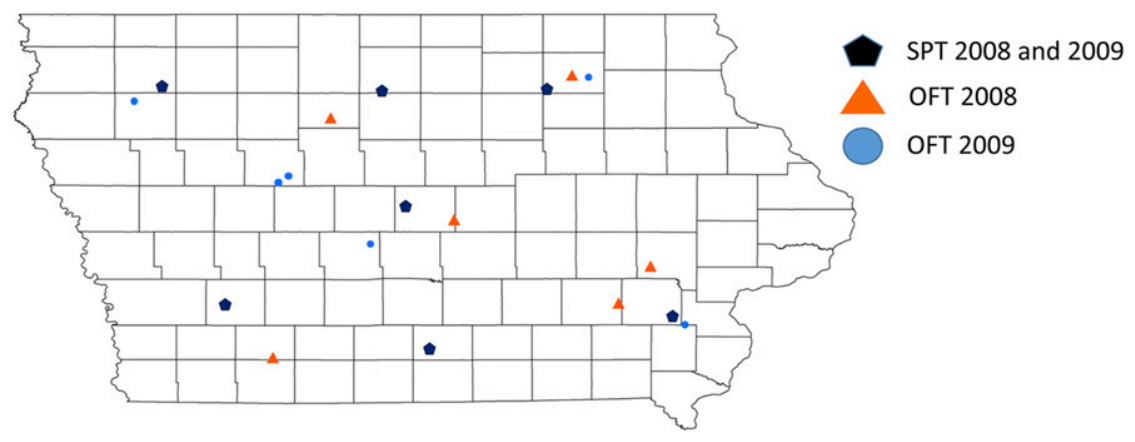

Fig. 1. Location of 12 small-plot trials (SPTs) and 12 on-farm trials (OFTs) in 2008 and 2009 used to conduct power analysis to estimate the desired sample size of trial locations and fungicide treatment replications. 
done using the $\mathrm{R}$ statistical software ( $\mathrm{R}$ Development Core Team 2016) with the lme4 package (Bates et al. 2014).

Power analysis. To evaluate how plot size affected soybean yield following foliar fungicide application in the absence of foliar fungal diseases, we selected two years (2008 and 2009) where disease levels, especially frogeye leaf spot, were negligible (less than 5\%) in Iowa (Bestor 2011; Wrather and Koenning 2009). In all OFTs and SPTs, no foliar diseases that would negatively affect yield were observed. Only two treatments, pyraclostrobin and the nontreated control, were used in these analyses. All locations were used in both years for the small plot trials. A subsample of six OFTs from each year, 12 locations in total from two years, was selected based on proximity to SPTs to represent similar environmental conditions observed in both types of trials (Fig. 1).

Since no empirical formulas exist to calculate power for multilocation experiments, Monte Carlo stochastic simulations with 500 random draws were used within a linear mixed effects model framework to estimate power values (Green and MacLeod 2016). The number of treatment replications and trial locations were estimated for overall yield differences of 33,67, 134, and $201 \mathrm{~kg} / \mathrm{ha}$ of yield response for both types of trials. The results of power analyses were presented as power curves showing the number of replications and trial locations with corresponding power values. A significant level of $10 \%$ was used in all power simulations. The desired sample size of trial locations and fungicide treatment replications was estimated using the power of $80 \%$.

\section{Results}

Disease and yield response. In general, foliar disease levels were extremely low in both fungicide treated and nontreated plots regardless of location or year. Disease data were collected only from SPT trials. Septoria brown spot was most frequently observed at all locations, but at low levels and limited to the lower third of the canopy (data not shown). Frogeye leaf spot was observed in northern Iowa locations at trace levels.

At the $10 \%$ significance level, yield responses to foliar fungicide were statistically significant in most study years; exceptions were 2011, 2012, and 2013 for OFTs; and 2009, 2012, 2013, and 2014 for SPTs (Table 2).

Yield responses to foliar fungicides were approximately similar regardless of trial type (Table 2). Overall, the average yield response across all site-years differed by $40 \%$, with SPTs producing a greater yield response than OFTs. At the $10 \%$ significance level, a paired $t$-test analysis for overall yield response indicated no statistically significant differences between trial type $(P=0.16)$. Greater yield responses were observed during the period between 2008 and 2011 and 2015 regardless of the trial type compared with the other years (Table 2).

Analysis of variance component. Standard deviations, $90 \%$ confidence intervals for mean standard deviations, and percentage of the total variation for each random component are presented in Table 3. Average yield response to fungicides was observed slightly over $200 \mathrm{~kg} / \mathrm{ha}$ in both trial types for the subset of 12 trials over two years and the yield responses between OFTs and SPTs were not statistically different $(P=0.16$ for a paired $t$-test).

The variation due to random effects of the year was the same regardless of trial type (Table 3). The mean standard deviations for the residual noise random component for OFTs was one half of that for the small-plot experiments. The associated confidence intervals did not overlap, indicating significant differences. All confidence intervals for the random components based on 12 OFTs were narrower than for those for the SPTs (Table 3).

With a larger dataset of 30 OFTs over two years, the random yield variation due to trial location was $27 \%$ greater than 12 SPTs over two years. (Table 3). Standard deviation values for the random effects estimated from the dataset with 30 OFTs were slightly smaller than those estimated from the dataset with 12 OFTs over two years.

Power analysis for multilocation trials. Power curves for the OFTs and SPTs were calculated using 12 OFTs and 12 SPTs observed in 2008 and 2009. The two years were used to incorporate year-to-year variability in the sample size calculations.

The power curves present the probability of detecting statistically significant yield responses of 33,67, 134, and $201 \mathrm{~kg} / \mathrm{ha}$ at a $10 \%$ significance level when these true yield responses are detected. With 12 OFTs over two years, three replications can detect a yield response of $134 \mathrm{~kg} / \mathrm{ha}$, while with the same number of trials, more than

Table 2. Comparison of soybean yield response to foliar fungicide applications in on-farm (OFTs) and small-plot trials (SPTs) in Iowa between 2008 and $2015^{\mathrm{a}}$

\begin{tabular}{|c|c|c|c|c|c|c|}
\hline \multirow[b]{2}{*}{ Year } & \multicolumn{2}{|c|}{$\begin{array}{l}\text { Number } \\
\text { of trials }\end{array}$} & \multicolumn{2}{|c|}{$\begin{array}{l}\text { Mean yield response } \\
(\mathrm{kg} / \mathrm{ha}) \text { and } P \text {-values }\end{array}$} & \multicolumn{2}{|c|}{$\begin{array}{c}\text { Standard } \\
\text { deviation for } \\
\text { trial mean } \\
\text { differences } \\
(\mathrm{kg} / \mathrm{ha})\end{array}$} \\
\hline & $\overline{\text { SPTs }}$ & $\overline{\text { OFTs }}$ & SPTs & OFTs & SPTs & $\overline{\text { OFTs }}$ \\
\hline 2008 & 7 & 77 & $324(<0.001)$ & $176(<0.001)$ & 155 & 149 \\
\hline 2009 & 5 & 46 & $134(0.111)$ & $119(<0.001)$ & 127 & 131 \\
\hline 2010 & 3 & 4 & $264(<0.001)$ & $239(0.017)$ & 149 & 181 \\
\hline 2011 & 6 & 2 & $275(0.002)$ & $113(0.113)$ & 382 & 62 \\
\hline 2012 & 7 & 28 & $83(0.259)$ & $13(0.404)$ & 132 & 103 \\
\hline 2013 & 7 & 15 & $83(0.344)$ & $50(0.350)$ & 190 & 117 \\
\hline 2014 & 7 & 27 & $9(0.913)$ & $119(<0.001)$ & 198 & 145 \\
\hline 2015 & 7 & 31 & $167(0.003)$ & $126(<0.001)$ & 116 & 117 \\
\hline Mean & 6.1 & 31.4 & $167(<0.001)$ & $119(<0.001)$ & & \\
\hline
\end{tabular}

${ }^{a}$ Fungicide included: pyraclostrobin (Headline, BASF), pyraclostrobin + fluxapyroxad (Priaxor, BASF), and trifloxystrobin + prothioconazole (Stratego YLD, Bayer CropScience). The yield response refers to the yield difference of fungicide treated plots minus nontreated control plots. All and any fungicides applied within a trial were averaged and compared with the nontreated control.

b The $P$-values in parentheses refer to the test of the null hypothesis: that the yield response is zero.

Table 1. List of cultivars planted and foliar fungicides applied in small-plot trials from 2008 to 2015

\begin{tabular}{lll}
\hline Year & \multicolumn{1}{c}{ Cultivars planted } & \multicolumn{1}{c}{ Fungicide products applied (rate in ml/ha) $^{\mathbf{a}}$} \\
\hline 2008 & Asgrow 2107, DairyLand 3155RR & Headline (438), Stratego YLD (292) \\
2009 & Cherokee 1029RR2Y, Navaho 720RR & Headline (438), Stratego YLD (292) \\
2010 & Asgrow 2430 & Headline (438), Stratego YLD (292) \\
2011 & Asgrow 2531, Legend 2279, Pioneer 92M32, Pioneer 92Y51, Pioneer 93M11, & Priaxor (292), Stratego YLD (292) \\
& Pioneer 93 Y40 & \\
2012 & Asgrow 2431, Kruger 1901, Pioneer 93M11, Pioneer 93Y22, Stine 19RA02 & Headline (438), Stratego YLD (292) \\
2013 & Asgrow 2534, Asgrow 2831, Asgrow 2933, Kruger 1901, Pioneer 93M11, & Headline (438), Priaxor (292), Stratego YLD (292) \\
& Pioneer 93Y80, Stine 19RA02 & Priaxor (292), Stratego YLD (292) \\
2014 & Asgrow 2931, Asgrow 2933RR, Kruger 1901, Kruger K2-2402, Pioneer & Priaxor (292), Stratego YLD (292) \\
& 92Y75, Pioneer 93Y60, Stine 20RD20 & \\
2015 & Asgrow 2431, Kruger K2-2402RR, Mycogen 5N206R2, Pioneer 92Y75, & \\
& Pioneer 92Y83, Pioneer 93Y60, Pioneer P22T69R & \\
\hline & active ingredients, Fungicide Resistance Action Committee (FRAC) group (http://www.frac.info), and manufacturer/supplier of the fungicides: Headline \\
(pyraclostrobin, 11, BASF Corporation, Research Triangle Park, NC), Priaxor (fluxapyroxad + pyraclostrobin, 7 + 11, BASF Corporation), Stratego YLD &
\end{tabular}
(prothioconazole + trifloxystrobin, $3+11$, Bayer CropScience, Research Triangle Park, NC). 
three times the number of treatment replications per trial would be needed to detect a $67 \mathrm{~kg} / \mathrm{ha}$ yield response and more than 25 replications are required to detect a $33 \mathrm{~kg} /$ ha yield response (Fig. 2A). Considering 12 experiments over two years, the power values to detect the same yield response were less for the SPTs (Fig. 2B) compared

Table 3. Variance component analysis for a subset of 30 and 12 on-farm (OFTs) and 12 small-plot trials (SPTs) testing yield response to pyraclostrobin applications in 2008 and 2009 in Iowa $^{\mathrm{a}}$

\begin{tabular}{lcc}
\hline Component & $\begin{array}{c}\text { Standard deviation } \\
\text { kg/ha }(\mathbf{9 0 \%} \text { CI) }\end{array}$ & $\begin{array}{c}\text { Percentage of the } \\
\text { total variance } \mathbf{( \% )}\end{array}$ \\
\hline 12 OFTs for 2 years & & \\
Year & $312.0(60.5 ; 1,539.0)$ & 5 \\
$\quad$ Location (year) & $458.0(315.8 ; 672.4)$ & 59 \\
Rep (year $\times$ location) & $134.4(100.8 ; 1747)$ & 28 \\
$\quad$ Residual noise & $168.0(147.9 ; 194.9)$ & 8 \\
12 SPTs for 2 years & & \\
Year & $390.1(67.3 ; 2,219.3)$ & 5 \\
Location (year) & $632.2(437.1 ; 934.8)$ & 57 \\
Rep (year $\times$ location) & $188.3(121.1 ; 302.6)$ & 22 \\
Residual noise & $343.0(295.9 ; 390.1)$ & 16 \\
30 OFTs for 2 years & & \\
Year & $74.0(40.4 ; 127.8)$ & 2 \\
Location (year) & $464.0(369.9 ; 578.4)$ & 84 \\
Rep (year $\times$ location) & $107.6(87.4 ; 134.5)$ & 5 \\
Residual noise & $154.7(148.0 ; 168.1)$ & 10 \\
\hline
\end{tabular}

${ }^{a}$ Mean yield responses for 12 OFTs, 12 SPTs, and 30 OFTs over two years were $215 \mathrm{~kg} / \mathrm{ha}$ (90\% CI: 168; 255), $228 \mathrm{~kg} / \mathrm{ha}(90 \%$ CI: 134; 329), and $188 \mathrm{~kg} / \mathrm{ha}$ (90\% CI: 168; 222), respectively.
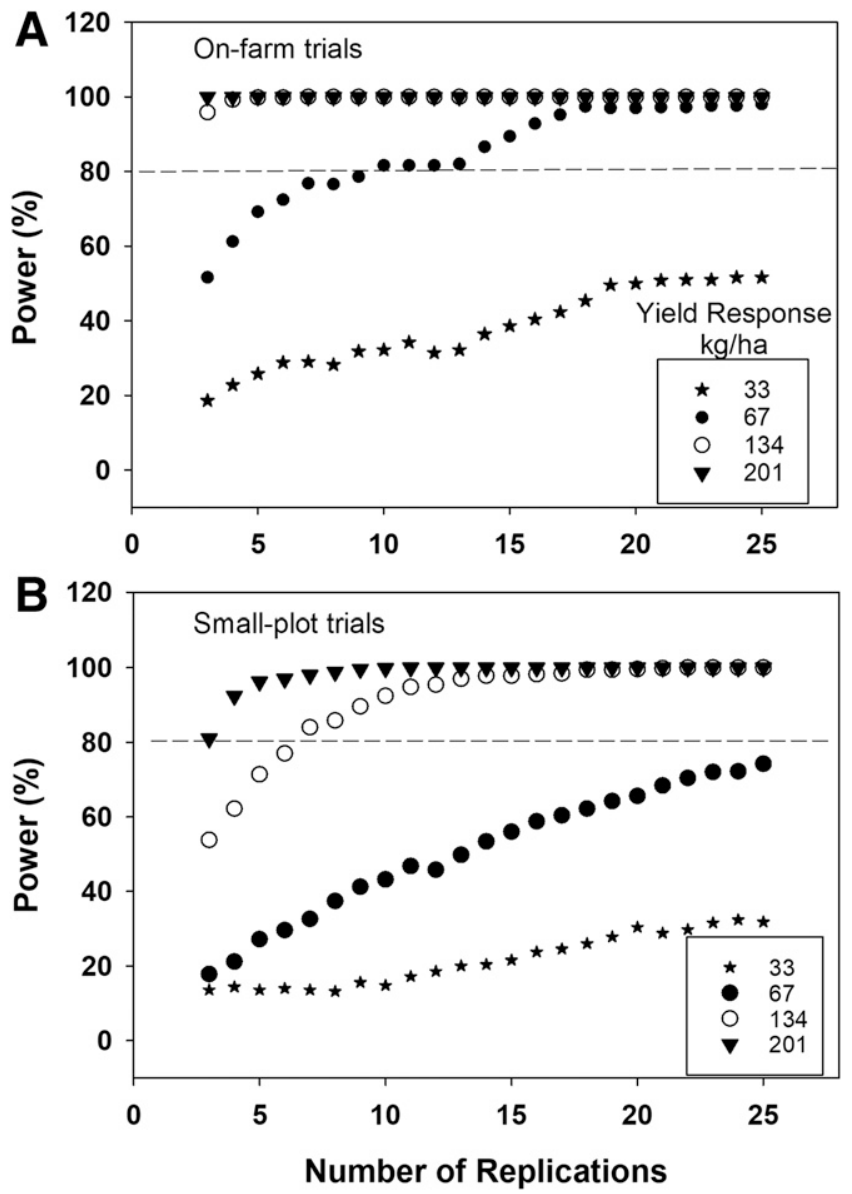

Fig. 2. Power curves for estimating the required number of treatment replications to detect statistically significant yield response of $33,67,134$, and $201 \mathrm{~kg} / \mathrm{ha}$ at $10 \%$ significance level based on 12 replicated on-farm trials with an average of six replications per trial $(\mathbf{A})$ and small-plot trials with an average of 5.6 replications per trial (B) conducted in 2008 and 2009. with the 12 OFTs (Fig. 2A). This implies that the sample size required was greater for SPTs compared with OFTs. In fact, almost double the number of treatment replications were required to detect a yield response of $67 \mathrm{~kg} / \mathrm{ha}$ for SPTs (25 replications) from 12 trials (Fig. 2B), compared with the 12 OFTs (15 replications) (Fig. 2A). While 25 and 15 treatment replications are not always feasible, small-plot experiments did have sufficient power to detect yield differences of 134 and $201 \mathrm{~kg} / \mathrm{ha}$ (Fig. 2B).

The number of trial locations required to detect a significant yield response of $33 \mathrm{~kg} / \mathrm{ha}$ in OFTs with more than five replications was estimated to be about 50, which was less than one third of trial locations that are required to detect a yield response of $67 \mathrm{~kg} / \mathrm{ha}$ with the same number of treatment replications (Fig. 3A). The number of trial locations required to detect the same yield response with more than five replications in SPTs (Fig. 3B) was always higher than that in OFTs. For example, the number of trial locations required to detect the $67 \mathrm{~kg} / \mathrm{ha}$ yield response with more than five replications in SPTs was four times higher than the number of trials required to detect the same yield response in OFTs.

\section{Discussion}

Fungicide manufacturers have promoted fungicide applications with specific active ingredients for physiological benefits in addition to disease management. As a result, fungicide use has increased substantially on soybean in the U.S. and Canada as a way to improve yield even in the absence of foliar disease (Mueller et al. 2013). The physiological effects of fungicides from the QoI class have previously been acknowledged by other studies (Grossmann et al. 1999; Wu and von Tiedemann 2001). However, several public studies evaluating foliar fungicide applications on crops under low disease environments or in the absence of
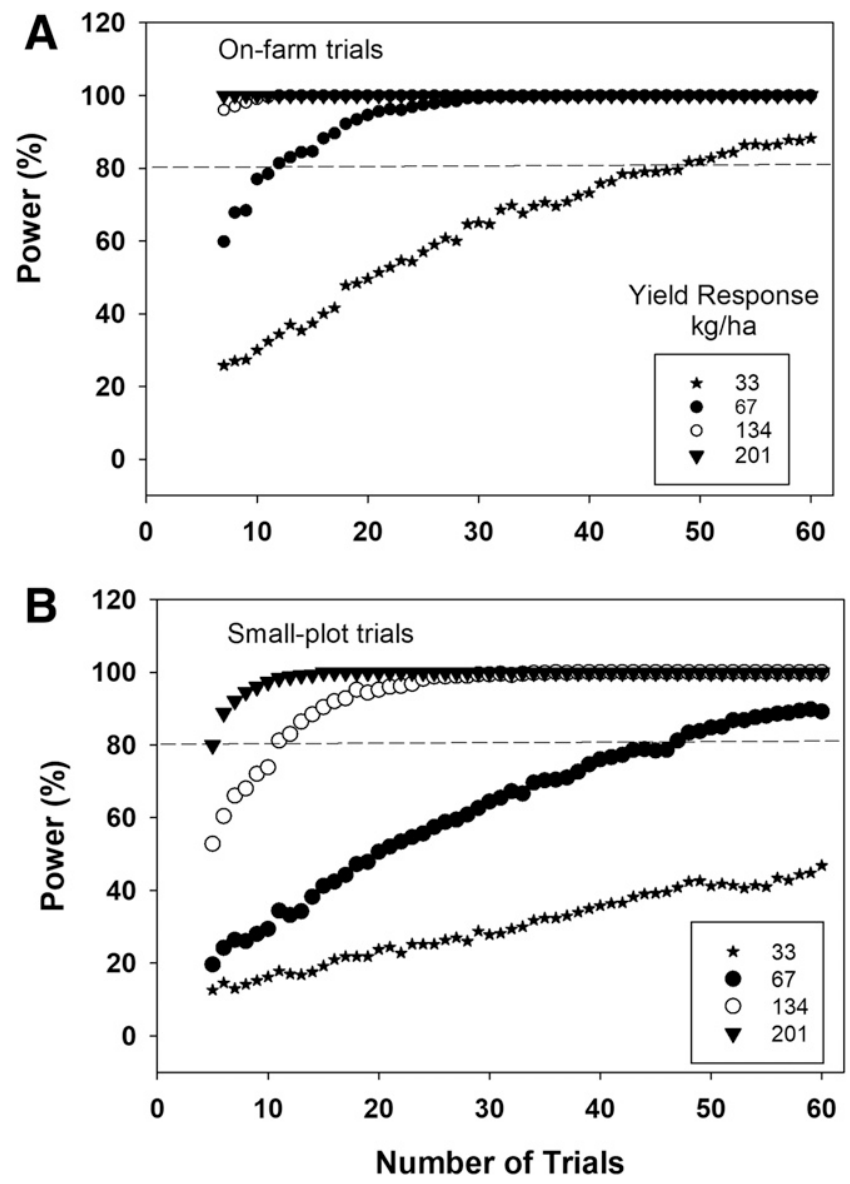

Fig. 3. Power curves for estimating the required number of trial locations to detect statistically significant yield response of $33,67,134$, and $201 \mathrm{~kg} / \mathrm{ha}$ at $10 \%$ significance level based on 12 replicated on-farm trials with an average of six replications per trial $(\mathbf{A})$ and small-plot trials with an average of 5.6 replications per trial (B) conducted in 2008 and 2009. 
disease have not consistently reported a positive yield response, or concluded that the yield response was not great enough to offset the fungicide cost (Kandel et al. 2016; Paul et al. 2011). Consistent with these previous reports, both OFTs and SPTs in the present study showed minimal yield responses to fungicide under low disease conditions.

Our comparison of 230 OFTs and 49 SPTs to evaluate the effect of foliar fungicides in Iowa between 2008 and 2015 resulted in similar yield responses. In the subset of data from 2008 and 2009, the yield response comparison between OFTs and SPTs were not statistically different. In contrast, a recent study published by Tedford et al. (2017) reported greater yield response in OFTs than SPTs and suggested that the yield response to fungicide increases with increasing plot size. Open alleys and borders affect yield estimates because of the reduced interplant competition. Compared with OFTs, small plots may have greater border and alley effects that may mask the potential yield response to fungicide because greater yield was harvested from the ends of the plot than the central area in a previous study (Vincelli and Lee 2015).

While the Tedford et al. (2017) study focused on yield response to fungicide in corn, the same principles would hold true for evaluating fungicide on soybean. Our analyses contradict the results of the above fungicide corn study, but suggest that the power of multilocational experiments should be considered, especially with reduced plot size and reduced number of trial locations or treatment replications. The number of trial locations contributed to the majority of the random yield variation (Table 3). Across two years, the variation due to trial locations was approximately 59\% in OFTs and 57\% in SPTs of the total random yield variation, likely due to different varieties planted, different yield potentials, different soil, and environmental factors involved. The random yield variation due to replication within each trial was double in SPTs than in OFTs, perhaps due to smaller plot size and greater plot-to-plot variation in SPTs. This is an important observation, demonstrating common differences associated with the accuracy of yield measurements in small plots and field length on-farm strips. The greater noise in SPTs could be due to larger small-scale soil variability or increased combine operator errors.

The current study illustrates the need to perform power analyses in both multilocational on-farm and small-plot experiments. Although yield responses were similar, the results determined that the power in detecting a statistically significant yield response is reduced in SPTs compared with OFTs. This is a critical observation because small plot experiments with less power may not detect the true yield difference or will require more replications or a greater number of experiment locations. To detect $67 \mathrm{~kg} / \mathrm{ha}$ yield response for small plot trials, 25 treatment replications were required while 15 replications were needed for OFT using 12 locations over two years. Both 25 and 15 treatment replications are not always possible to establish due to large spatial variability in small-plot and wide sprayer width or limited field size in on-farm experiments. Small-plot experiments did have sufficient power to detect yield differences of 134 and 201 $\mathrm{kg} / \mathrm{ha}$. It is noteworthy that a yield response of 67 to $134 \mathrm{~kg} / \mathrm{ha}$ is typically needed to pay for the cost of the application and fungicide in production soybean fields (Kandel et al. 2016).

Regardless of the differences between the two types of trials, it is important to realize that both methods of evaluating foliar fungicides have different utilities. Farmers learn better through OFTs by evaluating fungicides firsthand on their fields. Spatial analyses can be done to identify effects of soil properties and topography on yield response. Additional locations can be added with less difficulty to quantify potential interactions between yield response and environmental, management, or genetic factors in OFTs if farmers are part of a larger grower network or a university research group. Power analyses in a previous study reported that when the treatments were replicated, a smaller number of trial locations and replications was needed to detect a statistically significant yield response (Yan et al. 2002).

One benefit of small-plot experiments is that it is easier to include additional treatments at the same location or multiple locations. This is critical when evaluating different fungicide application timings or comparing multiple commercially available fungicides. Establishment of SPTs is often simpler than establishment of OFTs. Also, the collection of disease ratings and plant growth characteristics is easier in SPTs. There is more flexibility for when and where to establish SPTs. In addition, the overall cost per treatment in SPTs can be reduced because a smaller area is treated with fungicides.

The current study is in contrast to the recently published results suggesting that SPTs have reduced yield response than trials conducted in field scale OFTs (Tedford et al. 2017). However, it is important to note that the observed yield responses in both types of trials in the present study were observed in the absence of major foliar soybean disease. When there is high foliar disease pressure, the yield response to the fungicide could be different, more likely to be greater, which we were not able to investigate in this study. Our main focus in this study was to measure yield response to fungicide when foliar disease was absent or at low levels and to determine how OFTs and SPTs differ in terms of their power of detecting effect size. Our results suggest that researchers should acknowledge the differences in statistical power of detecting yield responses in different types of field experiments and should consider the power of fungicide experiments on soybean, especially with smaller plot sizes in situations with less foliar disease.

\section{Acknowledgments}

This research was partially funded by the Iowa Soybean Association, Bayer CropScience, and BASF. We thank Stith Wiggs, from Iowa State University, and the Iowa Soybean Association On-Farm Network staff for their technical support. In addition, we would like to thank the cooperating farmers and agronomists for executing the on-farm trials.

\section{Literature Cited}

Allen, T. W., Bradley, C. A., Sisson, A. J., Byamukama, E., Chilvers, M. I., Coker C. M., Collins, A. A., Damicone, J. P., Dorrance, A. E., Dufault, N. S., Esker, P. D., Faske, T. R., Giesler, L. J., Grybauskas, A. P., Hershman, D. E., Hollier, C. A., Isakeit, T., Jardine, D. J., Kemerait, R. C., Kleczewski, N. M., Koenning, S. R., Kurle, J. E., Malvick, D. K., Markell, S. G., Mehl, H. L., Mueller, D. S., Mueller, J. D., Mulrooney, R. P., Nelson, B. D., Newman, M. A., Osborne, L., Overstreet, C., Padgett, G. B., Phipps, P. M., Price, P. P., Sikora, E. J., Smith, D. L., Spurlock, T. N., Tande, C. A., Tenuta, A. U., Wise, K. A., Wrather, J. A., and Young-Kelly, H. 2017. Soybean yield loss estimates due to diseases in the United States and Ontario, Canada from 2010 to 2014. Plant Health Prog. 18:19-27.

Bates, D., Maechler, M., Bolker, B., and Walker, S. 2014. lme4: Linear mixedeffects models. http://CRAN.R-project.org/package=lme4

Bestor, N. 2011. The effect of fungicides on soybean in Iowa applied alone or in combination with insecticides at two application growth stages on disease severity and yield. M. S. Thesis, Iowa State University, Ames, IA.

Fehr, W. R., Caviness, C. E., Burmood, D. T., and Pennington, J. S. 1971. Stage of development descriptions for soybeans, Glycine max (L.). Merrill. Crop Sci. 11:929-931.

FRAC. 2017. Fungicide Resistance Action Committee Code List 2017: Fungicides sorted by mode of action (including FRAC code numbering). http://www.frac info/docs/default-source/publications/frac-code-list/frac-code-list-2017-final.pdf

Grichar, W. J. 2013. Soybean (Glycine $\max$ L.) response to fungicides in the absence of disease pressure. Int. J. Agron. 2013:561370.

Gelman, A., and Hill, J. 2007. Data analysis using regression and multilevel/ hierarchical models. Cambridge University Press, New York.

Green, P., and MacLeod, C. J. 2016. SIMR: an R package for power analysis of generalized linear mixed models by simulation. Methods Ecol. Evol. 7:493-498.

Grossmann, K., Kwiatkowski, J., and Casper, G. 1999. Regulation of phytohormone levels, leaf senescence and transpiration by the strobilurin kresoxim-methyl in wheat (Triticum aestivum). J. Plant Physiol. 154:805-808.

Kandel, Y. R., Mueller, D. S., Bestor, N. R. C., Bradley, C. A., Ames, K. A., Giesler, L. J., and Wise, K. A. 2016. Analyses of yield and economic response from foliar fungicide and insecticide applications to soybean in the North Central United States. Plant Health Prog. 17:232-238.

Kyveryga, P. M, Blackmer, T. M., and Mueller, D. S. 2013. When do foliar pyraclostrobin fungicide applications produce profitable soybean yield responses? Plant Health Prog. doi:10.1094/PHP-2013-0928-01-RS.

Mueller, D. S., Wise, K. A., Dufault, N. S., Bradley, C. A., and Chilvers, M. A., eds. 2013. Fungicides for Field Crops. American Phytopathological Society Press, St. Paul, MN.

Paul, P. A., Madden, L. V., Bradley, C. A., Robertson, A. E., Munkvold, G. P., Shaner, G., Wise, K. A., Malvick, D. K., Allen, T. W., Grybauskas, A., and Vincelli, P. 2011. Meta-analysis of yield response of hybrid field corn to foliar fungicides in the US corn belt. Phytopathology 101:1122-1132.

R Development Core Team. 2016. R: A Language and Environment for Statistical Computing. R Foundation for Statistical Computing, Vienna, Austria. http:// www.R-project.org/.

Rebetzke, G. J., Fischer, R. T. A., van Herwaarden, A. F., Bonnett, D. G., Chenu, K., Rattey, A. R., and Fettell, N. A. 2014. Plot size matters: interference from intergenotypic competition in plant phenotyping studies. Funct. Plant Biol. 41:107-118. 
Swoboda, C., and Pedersen, P. 2009. Effect of fungicide on soybean growth and yield. Agron. J. 101:352-356.

Tedford, E. C., Kriss, A. B., Geater, C., Saini, M., Battles, B., Smelser, R. B., and Fithian, W. A. 2017. Plot size can influence yield benefits from fungicides on corn. Crop Prot. 91:66-73.

Vincelli, P., and Lee, C. 2015. Influence of open alleys in field trials assessing yield effects from fungicides in corn. Plant Dis. 99:263-266.

Wang, K., Zhou, H., Wang, B., Jian, Z., Wang, F., Huang, J., Nie, L., Cui, K., and Peng, S. 2013. Quantification of border effect on grain yield measurement of hybrid rice. Field Crops Res. 141:47-54.
Wise, K., and Mueller, D. 2011. Are fungicides no longer just for fungi? An analysis of foliar fungicide use in corn. APSnet Feature Article.

Wrather, J. A., and Koenning, S. R. 2009. Effects of diseases on soybean yields in the United States 1996 to 2007. Plant Health Prog. doi:10.1094/PHP-20090401-01-RS

Wu, Y.-X., and von Tiedemann, A. 2001. Physiological effects of azoxystrobin and epoxiconazole on senescence and the oxidative status of wheat. Pestic. Biochem. Physiol. 71:1-10.

Yan, W., Hunt, L. A., Johnson, P., Stewart, G., and Lu, X. 2002. On-farm strip trials vs replicated performance trials for cultivar evaluation. Crop Sci. 42:385-392. 